\title{
PENGARUH DISIPLIN KERJA TERHADAP KINERJA PERANGKAT NAGARI DALAM PENGELOLAAN KEUANGAN NAGARI DI KECAMATAN BANUHAMPU DAN SUNGAI PUA
}

\author{
Rahmi Yanti \\ Jurusan Administrasi Publik, Fakultas Ilmu Sosial, Universitas Negeri Padang \\ rahmiyanti888@gmail.com
}

\begin{abstract}
ABSTRAK
This research aimed to determine the effect of work discipline on the performance of nagari apparatus in nagari financial management in Banuhampu and Sungai Pua subdistricts. Background of this research was that there were still many nagari apparatus came late to the office or leave the office during business hours. This research was carried out with quantitative approach. The population of this study was all nagari apparatus in Banuhampu and Sungai Pua subdistricts as many as 72 people consisted of Nagari Secretary, nagari treasurer,and four heads of nagari affairs. The sample in this study consisted of 61 respondents determined with Slovin formula with an error rate of 5\% and through proportionate stratified random sampling technique. The research data were collected through questionnaires with Likert scale measurements. Data of this research were analyzed with multiple linear regression test. The results of this research showed that there was the influence of work discipline on the performance of nagari aparatus in nagari financial management in Banuhampu and Sungai Pua
\end{abstract}

Keyword: Work Disciplne, Performance, Nagari Financial Management

\section{A. PENDahuluan}

Sejak munculnya sistem pemerintahan desentralisasi, desentralisasi membagi kekuasaan kepada pemerintah daerah. Desentralisasi tumbuh karena adanya pembangunan yang sepenuhnya tidak dapat dikendalikan oleh pemerintah pusat, sehingga pemerintah pusat memberikan wewenang atau otonomi kepada pemerintah daerah untuk merencanakan dan mengendalikan pembangunan daerah. Desentralisasi tidak hanya mencakup pembangunan daerah saja, tetapi juga penyelenggaraan pemerintahan dan semua urusan yang berkenaan dengan daerah tersebut, termasuk pengelolaan keuangan daerah (K. Permatasari et al, 2013)

Berkaitan dengan hal tersebut dalam meningkatkan kesejahteraan masyarakat, dilaksanakanlah program dana desa sesuai dengan asas desentralisasi dalam otonomi daerah. Dana desa dimulai tahun 2014, merupakan bagian dari APBN yang di peruntukkan bagi desa ditransfer melalui APBD Kabupaten /Kota. Tujuan dana desa berdasarkan Undang-Undang Nomor 6 Tahun 2014 Tentang Desa adalah meningkatkan pelayanan publik di desa, mengentaskan kemiskinan, memajukan perekonomian desa, mengatasi kesenjangan pembangunan antar desa, dan memperkuat masyarakat desa sebagai subjek dari pembangunan, namun lebih di prioritaskan kepada pelayanan dan pembangunan. Dalam pelaksanaannya sesuai asas otonomi Undang-Undang Nomor 23 Tahun 2014 
pemerintah daerah berwenang untuk mengelola dan memanfaatkan dana desa sesuai dengan kepentingan umum demi kesejateraan masyarakat, dan pengelolaan keuangan nagari harus di kelola secara baik dan benar.

Pemerintah Kabupaten Agam Sumatera Barat telah menurunkan tim untuk menilai delapan nagari atau desa adat di daerah itu tentang pengelolaan keuangan nagari pada 2017. Kepala Dinas Pemberdayaan Masyarakat dan Nagari (DPMN) Agam, Rahmad Lasmono mengatakan tim penilai berasal dari DPMN, Persatuan Wartawan Indonesia (PWI), Inspektorat, Badan Keuangan Daerah dan Bappeda. Delapan nagari yang dinilai tersebut memiliki nilai yang tinggi dari hasil penilaian yang dilakukan tim penilaian tingkat kecamatan. Tim ini akan turun ke nagari untuk memastikan kesesuaian asas pengelolaan keuangan nagari dengan fakta dan data di lapangan. Kemudian, tim menghitung kembali skor dari nagari tersebut dan skor akan dituangkan dalam berita acara hasil penghitungan skor nagari. Hasilnya Nagari Tigo Balai Kecamatan Matur Kabupaten Agam, terpilih sebagai nagari yang transparan dalam pengelolaan dana desa untuk lomba tingkat Provinsi Sumbar (Antara Sumbar, 2017).

Nagari sebagai sebuah organisasi, pasti memiliki tujuan, dimana proses dalam pencapaian tujuan tergantung pada bagaimana memanfaatkan sumber daya yang ada dalam organisasi tersebut terutama sumber daya manusia yang ada di dalamnya. Sumber daya manusia merupakan sumber daya terpenting pada setiap organisasi,terutama dalam pengelolaan keuangan nagari, dimana manusia sebagai penggerak dan pengelola sumbersumber daya lainnya. Seringkali kegagalan sebuah organisasi disebabkan karena sumber daya manusia yang ada di dalamnya tidak dikelola dengan baik, sehingga perlu adanya tata kelola sumber daya manusia dalam organisasi agar kinerja yang di hasilkan mampu mewujudkan tujuan organisasi, termasuk dalam hal disiplin kerja.

Disiplin kerja sebagai salah satu factor terpenting untuk meningkatkan kinerja pegawai, seperti yang di jelaskan Putra et al (2016) bahwa agar aktifitas yang ingin dilaksankan terlaksana dengan semestinya sesuai aturan yang telah ditetapkan maka diperlukan disiplin kerja, karena disiplin kerja mempengaruhi kinerja. Sedangkan menurut Leiden ( dalam Putra et al, 2016) menyatakan untuk mengatasi masalah kinerja yang buruk perlu diterapkannya disiplin kerja dengan baik karena disiplin kerja dapat memperkuat pengaruh prilaku kerja seseorang dalam kelompok atau organisasi

Berdasarkan hasil wawancara yang dilakukan pada hari senin tanggal 10 September 2018 dengan Bapak Wali Nagari Batagak Kecamatan Sungai Pua yaitu Hendri Dunan , dapat dipahami bahwa disiplin kerja perangkat nagari telah diatur dengan Peraturan Bupati Kabupaten Agam No 17 Tahun 2017 tentang Disiplin Kerja Aparatur Pemerintahan Nagari. Namun dalam pelaksanaanya Hendri Dunan mengatakan bahwa di kantor wali nagari ini tidak terlalu terikat dengan aturan yang ada. Hal ini dikarenakan adanya urusan lain perangkat nagari di luar urusan sebagai perangkat nagari, sehingga berakibat pada keterlambatan perangkat nagari ke kantor ataupun keluar pada saat jam kerja.

Berkaitan teori dan masalah yang dikemukakan diatas, dari hasil penelitian Pangarso \& Susanti (2016) dan penelitian Mailiana (2016) tentang pengaruh disiplin kerja terhadap kinerja, hasil penelitiannya menyatakan bahwa disiplin kerja mempunyai pengaruh yang signifikan terhadap kinerja pegawai. Sedangkan hasil penelitian Arianto (2013) menyatakan bahwa kedisiplinan kerja tidak berpengaruh terhadap kinerja. Dari penjelasan diatas dapat diketahui masih terdapat hasil penelitian yang berbeda dengan variabel yang sama. 
Berdasarkan masalah yang dipaparkan pada latar belakang, bahwa penulis tertarik melaksanakan penelitian di Kecamatan Banuhampu dan Sungai Pua. Penelitian ini merupakan intisari dari hasil penelitian skripsi serta merupakan bagian dari penelitian payung dari Syamsir (2017) yang berjudul Model Pembinaan Aparatur Pemerintahan Nagari dalam Pengelolaan Keuangan Nagari di Kabupaten Tanah Datar. Serta yang menjadi rumusan masalah dalam penelitian ini adalah Apakah terdapat pengaruh disiplin kerja (yang mencakup dua sub variabel aturan kerja dan etika kerja secara bersama-sama) terhadap kinerja perangkat nagari dalam pengelolaan keuangan nagari di Kecamatan Banuhampu dan Sungai Pua?

\section{B. TINJAUAN KEPUSTAKAAN}

\section{Disiplin kerja dan kinerja}

Putra et al (2016) menjelaskan disiplin kerja adalah bentuk ketaatan terhadap peraturan tata tertib yang ditetapkan. Zesbendri dan Aryanti dalam (Putra et al., 2016) menjelaskan menyatakan bahwa modal utama yang dapat mempengaruhi kinerja karyawan adalah disiplin. Sedangkan menurut J. A. Permatasari \& Mayowan (2015) disiplin kerja merupakan kesediaan karyawan untuk menaati aturan dan norma-norma yang berlaku di dalam perusahaan baik itu aturan yang tertulis ataupun aturan yang tidak tertulis. Dapat disimpulkan bahwa disiplin kerja mampu mempengaruhi kinerja pegawai dalam suatu organisasi dikarenakan disiplin kerja mampu mengontrol tata kerja pegawai agar bersungguh sungguh bekerja dan bekerja harus sesuai dengan aturan yang telah ditetapkan.

Anwar (2001) mengatakan yang mempengaruhi tingkat kedisiplinan karyawan dalam suatu organisasi adalah: tujuan dan kemampuan, teladan kepemimpinan, balas jasa, keadilan, waskat (pengawasan melekat), sanksi dan hukuman, ketegasan, serta hubungan kemenusiaan. Putra et al (2016) menyimpulkan bahwa dimensi yang digunakan untuk mengukur disiplin kerja adalah: aturan kerja yang terdiri dari indicator tingkat kehadiran, ketentuan jam kerja, dan intruksi dari atasan; kemudian etika kerja yang terdiri dari indikator tingkah laku karyawan terhadap atasan dan rekan kerja, kejujuran karyawan dalam bekerja, dan tanggungjawab karyawan terhadap pekerjaan.

Selanjutnya Edison dkk (dalam (Baiyulis et al, 2018) mengatakan kinerja adalah hasil pencapaian dari suatu proses yang mengacu dan diukur selama periode waktu tertentu berdasarkan ketentuan atau indikator-indikator kesepakatan yang telah ditetapkan sebelumnya, juga dijelaskan bahwa kinerja merupakan kunci efektif atau tidaknya suatu organisasi. Mulyadi (2015) kinerja (prestasi kerja) di definisikan sebagai hasil kerja yang dicapai oleh pekerja atau karyawan secara kualitas dan kuantitas yang ditetapkan sesuai dengan tugas dan tanggung jawab mereka. Dapat disimpulkan bahwa kinerja merupakan hasil atau pencapaian dari proses yang di lakukan pekerja sesuai dengan tugas dan tanggung jawab yang di emban.

Sedangkan Davis (dalam Mulyadi, 2015) faktor-faktor yang mempengaruhi kinerja yaitu kemampuan, motivasi, dan sikap mental. John Miner (dalam Edison, 2015) ada dimensi yang menjadi tolak ukur untuk mencapai atau melakukan penilaian kinerja yaitu: Kualitas, seperti tingkat kesalahan, kerusakan dan kecermatan, kuantitas, yaitu jumlah pekerjaan yang di hasilkan; Penggunaan waktu dalam kerja, seperti ketidakhadiran, 
keterlambatan, waktu kerja efektif/ jam kerja hilang, kerjasama dengan orang lain dalam bekerja.

Terkait dengan hubungan disiplin kerja dengan kinerja, Putra et al (2016) mengatakan bahwa disiplin kerja salah satu aspek yang mempengaruhi kinerja karyawan, dimana kedisiplinan diperlukan agar seluruh aktivitas yang sedang dan akan dilaksanakan berjalan sesuai mekanisme yang ditentukan. Kemudian menurut Leiden ( dalam Putra et al, 2016) menyatakan bahwa dengan ditegakkannya disiplin kerja maka dapat mengatasi masalah kinerja yang buruk serta memperkuat pengaruh prilaku kerja karyawan dalam kelompok dan organisasi

Banyak penelitian dilakukan untuk melihat pengaruh disiplin kerja terhadap kinerja dalam sebuah organisasi. Diantara penelitian yang telah dilakukan ditemukan hasil yang menyatakan bahwa disiplin kerja memberikan pengaruh terhadap kinerja seseorang atau kelompok. Seperti penelitian yang dilakukan oleh Pangarso \& Susanti, (2016), Mailiana (2016), Husain (2018) dan (Liyas \& Primadi, 2017). Sedangkan penelitian yang dilakukan Arianto (2013) menyatakan disiplin kerja tidak berpengaruh terhadap kinerja.

\section{Pengelolaan Keuangan Desa/Nagari dan Indikator Pengukur Kinerja dalam Pengelolaan Keuangan Nagari}

Keuangan nagari merupakan bagian dari keuangan daerah. Menurut Abdul Halim (dalam Putera (2016) menjelaskan bahwa keuangan daerah adalah kekayaan daerah yang bernilai,baik uang maupun barang sepanjang tidak dikuasai oleh daerah yang lebih tinggi sebagai hak dan kewajiban dari daerah tersebut.

Berdasarkan Peraturan Menteri Dalam Negeri Republik Indonesia Nomor 113 tahun 2014 Tentang Pengelolaan Keuangan Desa, bahwa pengelolaan keuangan desa merupakan kegitan yang berproses mulai dari perencanaan, pelaksanaan penatausahaan, pelaporan dan pertanggungjawaban keuangan desa. Serta dijelaskan bahwa yang berkuasan dan berwenang atas pengelolaan keuangan desa adalah kepala desa atau semacamnya dan perangkat desa atau disebut pelaksana teknis pengelolaan keuangan desa (PTPKD) yang nantinya membantu kepada desa dalam proses kegiatan pengelolaan keuangan desa.

Berdasarkan Peraturan Pemerintah Nomor 47 Tahun 2015 tentang Peraturan Pelaksanaan Undang-Undang Nomor 6 Tahun 2014 Tentang Desa pasal 1 ayat 8 yang dimaksud dengan dana desa adalah bagian dari APBN yang ditransfer kepada APBD Kabupaten/Kota serta diperuntukkan kepada desa untuk membiayai kegiatan pemerintahan yang berkaitan dengan penyelenggaraan pemerintahan, pelaksanaa pembangunan, pembinaan masyarakat serta pemberdayaan masyarakat.

Dalam bpkp (2015) dijelaskan bahwa asas-asas pengelolaan keuangan desa sesuai Permendagri Nomor 113 Tahun 2014 terdiri dari: pertama transparan sebagai bentuk dari keterbukaan kepada masyarakat agar masyarakat mendapatkan informasi yang seluasluasnya terkait dengan keuangan desa, serta maksud transparan yang diinginkan adalah informasi yang dibenarkan benar adanya, jujur serta tidak deskriminatif dalam penyelenggaraan pemerintahan desa tetap berlandaskan pada aruran perundangan yang berlaku; kedua akuntabel berarti dari kegiatan yang dilaksanakan hingga hasil akhir dari pengelolaan keuangan desa dapat dipertanggungjawabkan kepada public. ketiga partisipatif maksudnya adalah penyelenggaraan pemerintahan desa mengikutsertakan kelembagaan 
desa dan unsur masyarakat desa, dan keempat tertib dan disiplin anggaran yaitu pengelolaan keuangan desa harus mengacu pada aturan atau pedoman yang melandasinya.

\section{Metode Penelitian}

Metode penelitian yang digunakan dalam penelitian ini adalah metode penelitian kuantitatif, dikarenakan penelitian ini dimulai dari proses, hipotesis, turun kelapangan, analisa data dan kesimpulan data. Aspek yang digunakan dalam penelitian ini berupa pengukuran, perhitingan, menggunakan rumus serta kepastian dari data numeric. Populasi yang digunakan dalam penelitian ini adalah seluruh perangkat nagari yang ada pada seluruh nagari di Kecamatan Banuhampu dan Sungai Pua. Dengan menggunakan rumus Slovin diperoleh sampel yang digunakan sebanyak 61 responden dan teknik yang digunkan adalah teknik proportionate stratified randomsampling.

Data dalam penelitian ini dikumpulkan melalui penyebaran angket kepada responden dengan 4 opsi jawaban berdasarkan pengukuran menggunakan skala Likert yang terdiri dari (sangat setuju, setuju, kurang setuju, dan tidak setuju). kemudian analisis data dilakukan dengan teknik regresi linear berganda. Sebelum uji regresi perlu dilakukannya uji asumsi klasik sebagai persyaratan dalam uji regresi. Selain itu untuk mendapatkan gambaran umum tentang kedua variable juga digunakan frekuensi, mean, dan TCR (Tingkat Capaian Responden).

\section{Hasil Temuan serta Penjelasan}

\section{Temuan Penelitian}

Sesuai dengan yang dikemukakan dalam pendahuluan, terkait tiga pertanyaan penelitian atau rumusan masalah. Rumusan masalah mengenai apakah terdapat pengaruh disiplin kerja terkait aturan kerja dan etika kerja secara bersama-sama terhadap kinerja perangkat nagari dalam pengelolaan keuangan nagari di Kecamatan Banuhampu dan Sungai Pua? Untuk menjawab pertanyaan tersebut dapat dilihat hasil analisis data penelitian seperti disajikan pada tabel berikut :

Tabel 1. Secara Simultan pengaruh variable disiplin kerja (aturan kerja dan etika) terhadap kinerja perangkat nagari dalam pengelolaan keuangan nagari.

\begin{tabular}{lcrrrr}
\hline \multicolumn{5}{c}{ Model Summary $^{\mathbf{b}}$} \\
\hline Model & $\mathbf{R}$ & R Square & $\begin{array}{c}\text { Adjusted R } \\
\text { Square }\end{array}$ & $\begin{array}{c}\text { Std. Error of } \\
\text { the Estimate }\end{array}$ & Durbin-Watson \\
\hline 1 & $.613^{\text {a }}$ & .376 & .355 & .33081 & 1.500 \\
\hline a. Predictors: (Constant), rata-rata etika kerja, rata rata aturan kerja \\
\hline b. Dependent Variable: rata-rata pengelolaan keuangan nagari \\
\hline
\end{tabular}


Tabel 2 Hasil Uji Anova (F) pengaruh variable disiplin kerja terhadap kinerja perangkat nagari dalam pengelolaan keuangan nagari

\begin{tabular}{|c|c|c|c|c|c|c|}
\hline \multicolumn{7}{|c|}{ ANOVA $^{\mathrm{b}}$} \\
\hline Model & & $\begin{array}{l}\text { Sum of } \\
\text { Squares }\end{array}$ & Df & $\begin{array}{l}\text { Mean } \\
\text { Square }\end{array}$ & $\mathbf{F}$ & Sig. \\
\hline \multirow[t]{3}{*}{1} & Regression & 3.831 & 2 & 1.915 & 17.502 & $.000^{\mathrm{a}}$ \\
\hline & Residual & 6.347 & 58 & .109 & & \\
\hline & Total & 10.178 & 60 & & & \\
\hline \multicolumn{7}{|c|}{ a. Predictors: (Constant), rata-rata etika kerja, rata rata aturan kerja } \\
\hline \multicolumn{7}{|c|}{ b. Dependent Variable: rata-rata pengelolaan keuangan nagari } \\
\hline
\end{tabular}

Pada tabel 1 nilai Adjusted $R$ Square yang diperoleh dari analisis regresi adalah sebesar 0,355 . Artinya, secara simultan besarnya pengaruh variabel disiplin kerja yang mencakup dua sub variable (aturan kerja dan etika kerja) terhadap kinerja perangkat nagari dalam pengelolaan keuangan nagari adalah sebesar 35,5\% Sementara sebesar 64,5\% factor yang mempengaruhi tidak diteliti dalam penelitian ini. Selain itu, bila diperhatikan hasil Uji Anova pada Tabel 2 di atas dapat pula dilihat bahwa hasil atau angka signifikansi pengaruh menunjukkan angka $0,000^{\mathrm{a}}$. Artinya, kebenaran kesimpulan hasil uji regresi ini dapat dipercaya sampai $100 \%$.

Selanjutnya, jawaban dari rumusan masalah dalam penelitian ini adalah: Apakah terdapat pengaruh secara sendiri-sendiri dari aspek aturan kerja dan etika kerja (sebagai sub variabel disiplin kerja) terhadap kinerja perangkat nagari dalam pengelolaan keuangan nagari di Kecamatan Banuhampu dan Sungai Pua? Secara ringkas, hasil pengujian regresi untuk menjawab rumusan masalah dijelaskan berdasarkan Tabel 3 berikut ini.

Tabel 3.Pengaruh sub variabel aturan kerja dan etika kerja secara sendiri-sendiri terhadap kinerja perangkat nagari dalam pengelolaan keuangan nagari

\begin{tabular}{lcccc}
\hline \multicolumn{1}{c}{ Sub Variabel } & R & R Square & $\begin{array}{c}\text { Adjusted } \\
\text { R Square }\end{array}$ & Sig. \\
\hline Aturan kerja & $.489^{\mathrm{a}}$ & .239 & .226 & $.000^{\mathrm{a}}$ \\
\hline Etika kerja & $.589^{\mathrm{a}}$ & .347 & .336 & $.000^{\mathrm{a}}$
\end{tabular}

Berdasarkan tabel tersebut diketahui bahwa, nilai Adjusted $R$ Square untuk sub variabel aturan kerja adalah sebesar 0,226. Hal ini berarti bahwa pengaruh aturan kerja terhadap pengelolaan keuangan nagari sebesar 22,6\%. Selanjutnya nilai Adjusted $R$ Square untuk sub variabel etika kerja adalah sebesar 0,336 . Berarti bahwa pengaruh etika kerja terhadap pengelolaan keuangan nagari sebesar 33,6\%. Selain itu, bila diperhatikan hasil uji Anova pada hasil atau angka signifikansi pengaruh menunjukkan angka $0,000^{\mathrm{a}}$ untuk dua 
sub-variabel. Ini berarti bahwa kebenaran kesimpulan hasil uji regresi ini dapat pula dipercaya sampai $100 \%$.

\section{Pembahasan}

Hasil penelitian mengenai pengaruh disiplin kerja terhadap kinerja perangkat nagari dalam pengelolaan keuangan nagari di Kecamatan Banuhampu dan Sungai Pua membuktikan disiplin kerja perpengaruh terhadap kinerja perangkat nagari dalam pengelolaan keuangan nagar di Kecamatan Banuhampu dan Sungai Pua, baik secara simultan maupun secara sendiri-sendiri dari dua sub variabel disiplin kerja yaitu aturan kerja dan etika kerja. Secara bersama-sama pengaruh aturan kerja dan etika kerja terhadap kinerja perangkat nagari dalam pengelolaan keuangan nagari di Kecamatan Banuhampu dan Sungai Pua menghasilkan angka signifikansi 0,000 dan nilai Adjust $R$ Square sebesar 0,355 sehingga dapat dikatakan bahwa kontribusinya adalah sebesar 35,5\% dan nilai $\mathrm{R}$ sebesar 0,613 maksudnya bahwa pengaruh variabel disiplin kerja terhadap kinerja perangkat nagari dalam pengelolaan keuangan nagari di Kecamatan Banuhampu dan Sungai Pua sebesar 61,3\%. Dari penjelasan di atas dapat ditarik kesimpulan bahwa baik secara parsial maupun secara bersama-sama disiplin kerja memiliki pengaruh secara signifikan terhadap kinerja perangkat nagari dalam pengelolaan keuangan nagari di Kecamatan Banuhampu dan Sungai Pua.

Selanjutnya hasil uji secara sendiri-sendiri pengaruh sub-variabel aturan kerja (X1), dan etika kerja (X2) terhadap pengelolaan keuangan nagari menghasilkan angka signifikansi masing-masing sebesar 0,000 dan nilai Adjust $R$ Square masing-masing sebesar 0,226 (22,6\%) untuk aturan kerja, 0,336 (33,6\%) untuk etika kerja. Oleh karenanya dapat dikatakan bahwa kontribusi aturan kerja terhadap pengelolaan keuangan nagari sebesar $23 \%$, dan etika kerja sebesar 34\%.

Dengan memperhatikan hasil penelitian ini dapat dipahami bahwa hasil penelitian ini dapat membuktikan dan ikut memperkuat teori-teori dan temuan penelitian yang sudah ada, seperti dikemukakan oleh Putra et al (2016) yang mengatakan bahwa disiplin kerja merupakan salah satu aspek yang mempengaruhi kinerja karyawan ,. Kemudian menurut Leiden ( dalam Putra et al, 2016) menyatakan bahwa dengan ditegakkannya disiplin kerja maka dapat mengatasi masalah kinerja yang buruk. Selain itu hasil dari penelitian Pangarso \& Susanti (2016) menunjukkan bahwa terdapat hubungan yang sangat erat antara disiplin kerja dengan kinerja pegawai, serta penelitian dari Mailiana, (2016) menyatakan terdapat pengaruh yang signifikan variable disiplin kerja terhadap kinerja pegawai. Hal ini berarti disiplin kerja yang baik tentu akan dapat memengaruhi kinerja seseorang menjadi lebih baik sehingga menjadikan sebuah organisasi juga lebih baik.

\section{E. Penutup}

Berdasarkan hasil penelitian dan pembahasan yang telah diuraikan sebelumnya, dapat disimpulkan bahwa hasil penelitian ini menunjukkan bahwa variable aturan kerja dan etika kerja memberikan pengaruh yang signifikan terhadap kinerja pengelolaan keuangan nagari 
di Kecamatan Banuhampu dan Sungai Pua baik secara simultan maupun secara sendirisendiri, serta pengaruh aturan kerja dan etika kerja terhadap kinerja perangkat nagari dalam pengelolaan keuangan nagari menunjukkan angka signifikansi 0,000. Dengan nilai signifikansinya lebih kecil dari 0,05 ini maka Ho ditolak dan Ha diterima.

Berdasarkan uraian dari hasil dan kesimpulan penelitian diatas, ada beberapa saran yang penulis kemukakan diantaramya:

1. Wali nagari sebagai pemimpin sebuah nagari agar lebih tegas dalam menerapkan aturan-aturan yang telah ditetapkan berdasarkan PERDA kepada perangkat nagari.

2. Diharapkan adanya pengawasan dari pemerintah daerah terkait dengan disiplin kerja perangkat nagari maupun aparatur pemerintah.

Dari penelitian yang penulis lakukan, penulis menyadari masih adanya kesalahan ataupun kelemahan dalam pelaksanaan penelitian ini, oleh karena itu penulis harapkan perbaikan penelitian oleh peneliti selanjutnya baik deri segi pelaksanaan penelitian maupun dari hasil penelitian agar melakukan penelitian yang lebih baik mendalam dengan melibatkan berbagai variabel lain yang mungkin juga dapat berpengaruh terhadap kinerja pengelolaan keuangan nagari di Kecamatan Banuhampu dan Sungai Pua.

\section{DAFTAR KEPUSTAKAAN}

\section{Referensi Dari Buku}

A.A. Anwar Prabu Mangkunegara.2001. Manajemen Sumber Daya Manusia , Bandun: Remaja Rosdakarya

Mulyadi.(2015).Manajemen Sumber Daya Manusia . Jakarta:In Media

BPKP(2015). Petunjuk Pelaksanaan Bimbingan \& Konsultasi Pengelolaan Keuangan Desa. Deputi Bidang Pengawasan Penyelenggaraan Keuangan Daerah

Syamsir.(2017). "Model Pembinaan Aparatur Pemerintahan Nagari Dalam Pengelolaan Keuangan Nagari Di Kabupaten Tanah Datar Provinsi Sumatera Barat". Laporan Penelitian:Universitas Negeri Padang.

\section{Referensi dari Jurnal}

Arianto, D. A. N. (2013). Pengaruh Kedisiplinan, Lingkungan Kerja Dan Budaya Kerja Terhadap Kinerja Tenaga Pengajar. Jurnal Economia, 9, 191-200. Https://Doi.Org/10.21831/ECONOMIA.V9I2.1809

Baiyulis, Syamsir, \& Jumiati. (2018). Pengaruh Kepuasan Kerja Terhadap Kinerja

Perangkat Nagari Dalam Pengelolaan Keuangan Nagari Di Kecamatan Sungai Tarab Dan Salimpaung. Journal Of Education On Social Science, 2(2), 73-84.

Husain, B. A. (2018). Pengaruh Motivasi Kerja Dan Disiplin Kerja Terhadap Kinerja Karyawan Pada Pt Indah Kiat Pulp \& Paper. Jurnal Ekonomi Efektif, 1(1), 24-42.

Liyas, J. N., \& Primadi, R. (2017). Pengaruh Disiplin Kerja Terhadap Kinerja Karyawan Pada Bank Perkreditan Rakyat. Al Masraf: Jurnal Lembaga Keuangan Dan Perbankan, 2(1), 1-10. Https://Doi.Org/10.1016/J.Nanoen.2012.08.008

Mailiana. (2016). Pengaruh Disiplin Kerja Terhadap Kinerja Pegawai Dinas Pengelolaan Pasar Kota Bajarmasin. Jurnal Ekonomi Manajemen, 10(1), 123-134. 
Pangarso, A., \& Susanti, P. I. (2016). Pengaruh Disiplin Kerja Terhadap Kinerja Pegawai Di Biro Pelayanan Sosial Dasar Sekretariat Daerah Provinsi Jawa Barat. Jurnal Manajemen Teori Dan Terapan Tahun, 9(2), 145-160. Https://Doi.Org/10.1108/Eb045146

Permatasari, J. A., \& Mayowan, M. A. M. Y. (2015). Pegaruh Disiplin Kerja Dan Motivasi Kerja Terhadap Prestasi Kerja Karyawan. Jurnal Administrasi Bisnis, 25(1), 7-9.

Permatasari, K., Pratiwi, R. N., \& Suwondo. (2013). Otonomi Desa Dalam Pengelolaan Asset Desa. Jurnal Administrasi Publik, 1(6), 1213-1219.

Putera, R. E. (2016). Pengelolaan Keuangan Daerah Yang Transparan Di Kabupaten Tanah Datar Dalam Melaksanakan Desentralisasi Fiskal. Sosiohumaniora, 18(3), 261-269. Https://Doi.Org/10.2307/638116

Putra, W. I., Suwendra, W., \& Bagia, W. (2016). Pengaruh Tingkat Pendidikan Dan Disiplin Kerja Terhadap Kinerja Karyawan. E-Journal Bisma Universitas Pendidikan Ganesha Jurusan Manajemen, 4(1).

S Syamsir.2016.The Influence of Public Service Motivation on Service Quality of Civil Servant In West Sumatra Indonesia.European Journal of Economics And Business Studies 2 (2), 33-14.

F Fatmaliza, S Syamsir, J Jumiati.2018. KONTRIBUSI PENGALAMAN KERJA TERHADAP KINERJA PERANGKAT NAGARI DALAM PENGELOLAAN KEUANGAN NAGARI DI KABUPATEN TANAH DATAR. Journal of Education on Social Science (JESS) 2 (2),85-98.

\section{Referensi Dari Peraturan Pemerintah}

Undang -Undang Nomor 23 Tahun 2014 Tentang Pemerintahan Daerah

Undang-Undang Nomor 6 Tahun 2014 Tentang Desa

Permendagri Nomor 113 Tahun 2014 Tentang Pengelolaan Keuangan Desa

\section{Referensi dari internet}

Antara sumbar.2017. "agam nilai delapan nagari tentang pengelolaan keuangan nagari" .https://sumbar.antaranews.com/berita/215530/agam-nilai-delapan-nagari-tentangpengelolaan-keuangan". Diakses sabtu 11 November 2017

Antara sumbar .2017. "HPN 2018 - Tim Provinsi Nilai Pengelolaan Dana Desa NagariTigoBalaiAgam” .https://sumbar.antaranews.com/berita/217232/hpn-2018--timprovinsi-nilai-pengelolaan-dana-desa-nagari-tigo-balai-agam. Diakses rabu 13 desember 